\title{
The effect of dams on the larval abundance and composition of four carp species in key river systems in China
}

\author{
Maolin Hu • Qi Hua • Huiming Zhou • Zhiqiang Wu • \\ Xiaoping Wu
}

Received: 13 February 2014 / Accepted: 25 August 2014 / Published online: 31 August 2014

(C) The Author(s) 2014. This article is published with open access at Springerlink.com

\begin{abstract}
The four species of carp present in China (grass carp, black carp, silver carp and bighead carp) are all commercially important freshwater fish species. However, the construction of large-scale hydraulic projects, such as dams, along with other anthropogenic changes to river systems has resulted in the rapid decline in abundance of all four carp species. Indeed, the effect of dams on the reproduction of the four species has become a highly sensitive issue in China. Historically, the Ganjiang River contained 12 spawning grounds for the four species. After the construction of the Wan'an Dam, however, four of these spawning areas were flooded. Three additional dams are currently under construction below the Wan'an Dam. While it is clear that these dams will further alter the hydrological regime in the river, there is currently little information available for the management and protection
\end{abstract}

\footnotetext{
M. Hu $(\bowtie) \cdot X$. Wu

School of Life Sciences, Nanchang University, Nanchang, Jiangxi Province 330031, People's Republic of China e-mail: humaolin@ncu.edu.cn

Q. Hua

Jiangxi Aquaculture Technology Extending Stations, Nanchang, Jiangxi Province 330046,

People's Republic of China

H. Zhou

Jiangxi Fisheries Research Institute, Nanchang, Jiangxi

Province 330039, People's Republic of China

$\mathrm{Z} . \mathrm{Wu}$

College of Environmental Science and Engineering, Guilin University of Technology, Guilin, Guangxi Zhuang

Autonmous Region 541004, People's Republic of China
}

of carp in this river. In this study, we review published studies to characterize the patterns of larval abundance of the four species of carp in relation to environmental correlates in the Ganjiang River to provide baseline information that can be used to conserve these species.

Keywords Domestic Chinese carps · Spawning ground · Dam · Ganjiang River

\section{Introduction}

Four species of carp (the grass carp, Ctenopharyngodon idella; black carp, Mylopharyngodon piceus; silver carp, Hypophthalmichthys molitrix; bighead carp, Hypophthalmichthys nobilis), referred to in China as the "four domestic fishes", are all commercially important freshwater fish species in China. In the 20th century, $60 \%$ of the entire catch of freshwater fishes in China consisted of the "four domestic fishes" (Wu et al. 1992). These species grow and mature in floodplain lakes. Adults naturally migrate into rivers during the spawning season (April - July), triggered by increased temperatures $\left(>18{ }^{\circ} \mathrm{C}\right)$ and rising water levels during the flood season. The fertilized eggs hatch and the larvae develop during downstream drift. Larvae and juveniles then enter nursery areas in the floodplain lakes (Yi and Liang 1964; Zhang et al. 2012).

In order to prevent flooding and drought, dams have been built in most of China's rivers and lakes, and their use for power generation and irrigation causes severe fluctuations in water levels. These activities also 
influence the distribution and productivity of aquatic biotic communities (Zhang and Mei 1996). In particular, dams impact aquatic biota through flow and temperature modifications, water chemistry changes, and impediments to migration (McAllister et al. 2001; Nilsson et al. 2005). These dams, along with the impacts of other anthropogenic changes, including water pollution, overfishing, the reclamation of lakes for farmland, and the loss of connectivity between floodplain lakes and rivers, have resulted in the rapid decline in abundance of all four carp species. Indeed, the effect of dams on the survival and reproduction of the four carp species has become a highly sensitive issue in China (Duan et al. 2009). In this study, we review published studies to characterize the patterns of larval abundance of the four species of carp in relation to environmental correlates in the Ganjiang River to provide baseline information on the reproductive ecology of these species that can be used to ensure their conservation.

\section{Materials and methods}

The Yangtze River is the longest river in China and the third longest river in the world. It originates from alpine springs on the slopes of the Geladandong Mountains on the Qinghai-Xizhang (Tibetan) Plateau, and follows a sinuous easterly route before emptying into the East China Sea at Shanghai: a length of $6,300 \mathrm{~km}$. The river has more than 3,000 tributaries and 4,000 lakes. Lakes interlace with the Yangtze River and its tributaries to form a complete riverine-lacustrine network (Fu et al. 2003). The Yangtze River is the most important breeding habitat for the "four domestic fishes". Historically, the catch of the four domestic fishes in the Yangtze River accounted for $63 \%$ of the total natural fry production in all of China (Wu et al. 1992).

Many researchers have investigated the reproductive ecology of the four domestic fishes in the Yangtze River. This provides an ideal opportunity to investigate the reproductive ecology of the four domestic fishes. In this study, we review the current knowledge on the larval abundance of the four domestic species to ascertain the level of threat posed by the construction of dams to their continued persistence. The data in this study was obtained from Yi and Liang (1964), Zhou et al. (1980), Yu (1985), Yi et al. (1988), Yu et al. (1988), Tian (1989), Zeng (1990), Qiu et al. (2002), Li et al. (2006), Duan et al. (2009), Liu et al. (2009), Xie et al. (2009) and Wan et al. (2011).

\section{Results and discussion}

Changes in the larval abundance of the four domestic Chinese carp species in the Yangtze River

In the 1960s, there were a total of 36 spawning grounds distributed in the mainstream of the Yangtze River from Chongqing to Pengze $(1,695 \mathrm{~km})$, and the annual mean egg production was over 100 billion (Yi and Liang 1964). At that time, the breeding season lasted from May to July (Yi and Liang 1964). After the construction of the Gezhouba Water Control Project in the 1980s, six spawning areas were flooded and annual egg production was reduced to approximately 20 billion (Yu et al. 1988). From 1997-2002, there was a marked decline in the mean number of larvae produced, to just 2.5 billion (range 1.93.6 billion; Duan et al. 2009). The completion and closure of the Three Gorges Dam (on June 1, 2003) has drastically changed the hydrology of the Yangtze River and further negatively impacted on larval abundance of carp species (Fu et al. 2003; Xie 2003; Xie et al. 2007). Total larval abundance in May and June of 2004 was reported to be 0.339 billion, just $13.4 \%$ of the average larval abundance reported before the dam's closure. More worryingly, by 2005, larval abundance had dropped to 0.105 billion, which was just $4.2 \%$ of the average larval abundance recorded over the previous years, and the lowest ever recorded (Duan et al. 2009).

From 1997-2002, prior to the closure of the Three Gorges Dam, grass carp and black carp were the most abundant larvae species observed, with grass carp accounting for between 60 and $85 \%$ of the larvae, while silver carp and bighead carp accounted for $21.81 \%$ and $8.40 \%$ of the larvae observed, respectively. Following the dam's closure, the composition of larvae has undergone great changes, such that today silver carp dominate the larvae present (accounting for $66.11 \%$ of larvae in 2005; Duan et al. 2009).

Changes in larval abundance of the four domestic Chinese carp species in the Hanjiang River, a tributary of the Yangtze River

The Hanjiang River is the second longest tributary of the Yangtze River and one of the most important breeding locations for the four domestic fishes. As in the Yangtze River itself, the construction of dam hydraulic projects in the Hanjiang River Basin has altered the spawning locations and larval abundance of the four domestic 
fishes (Borutsky et al. 1959). A study conducted after the construction of the Danjiangkou Dam (completed in 1968), showed that there were nine spawning grounds in the middle-lower reaches of the Hanjiang River and a further ten spawning grounds in its upper reaches (Zhou et al. 1980). Egg production was estimated to be 1.36 billion in 1976 and 17.13 billion in 1977 (Zhou et al. 1980). The construction of the Wangpuzhou Dam (closed on February 1998) and the Middle Route Project of South to North Water Diversion drastically changed the hydrology of the middle-lower reaches of the Hanjiang River. This caused egg production of the four domestic fishes to decrease sharply: in 2004 egg production was 93.30 million, just $6.86 \%$ of that recorded in 1976 ( $\mathrm{Li}$ et al. 2006). By 2007, egg production had dropped further to 32.45 million (Xie et al. 2009). The current production of egg and larvae in the middle-lower reaches of the Hanjiang River is unknown 2009 (Wan et al. 2011).

In addition, studies show that the species composition of larvae in the middle-lower reaches of the Hanjiang River also changed dramatically. Grass carp was the most abundant larvae of the four domestic fishes in 1976 , accounting for $60.58 \%$ of the larvae, with black carp, silver carp, and bighead carp accounting for $21.98 \%, 16.18 \%$, and $1.26 \%$, respectively (Zhou et al. 1980). By 2007, however, the proportion of silver carp had increased to $53.40 \%$ of the total larvae (Xie et al. 2009).

The significance to investigate larval abundance of the four domestic Chinese carp species and environmental correlates in the Ganjiang River

The hydrologic regime, which influences aquatic biodiversity via several interrelated mechanisms operating over different spatial and temporal scales (Bunn and Arthington 2002), plays a major role in determining the biotic composition, structure, and function of aquatic, wetland, and riparian ecosystems (Richter et al. 1996; Poff et al. 1997). Fishes have adapted to natural flow regimes through different modes, such as life history, behavioral and morphological features (Lytle and Poff 2004), and fish diversity may be affected by changes to the characteristics of hydrologic regime (Huang et al. 2011). Unsurprisingly, therefore, hydrological regimes will change following the construction of dams.

Poyang Lake is the largest freshwater body in China, and is linked to the Yangtze River by a narrow outlet
(Fig. 1). Five rivers flow into Poyang Lake: Ganjiang River, Xinjiang River, Fuhe River, Raohe River and Xiuhe River. Poyang Lake is a main nursery ground of the four domestic fishes and from June to October every year a large number of juvenile fish (3.1 million in 2010) immigrate into the Poyang Lake from the Yangtze River (Hu et al. 2011). In the near future, the Poyang Lake Dam will be constructed to control water levels in Poyang Lake. This dam will cut off its connection with the Yangtze River and prevent the movement of the four domestic fishes. The larvae cannot pass from the river into the lake, and the movement of adult fish cannot move from the lake into the river to spawn. Hence, the movement of larvae of the four domestic fishes from other rivers that are linked to Poyang Lake (such as the Ganjiang River) will be critical for the protection and recovery of populations of the four domestic fishes in the Poyang Lake. A previous study indicates that the Poyang Lake silver carp population consisted mainly of the Ganjiang River population (Wang et al. 2003). However, in the Ganjiang River, a further three dams are under construction below the Wan'an

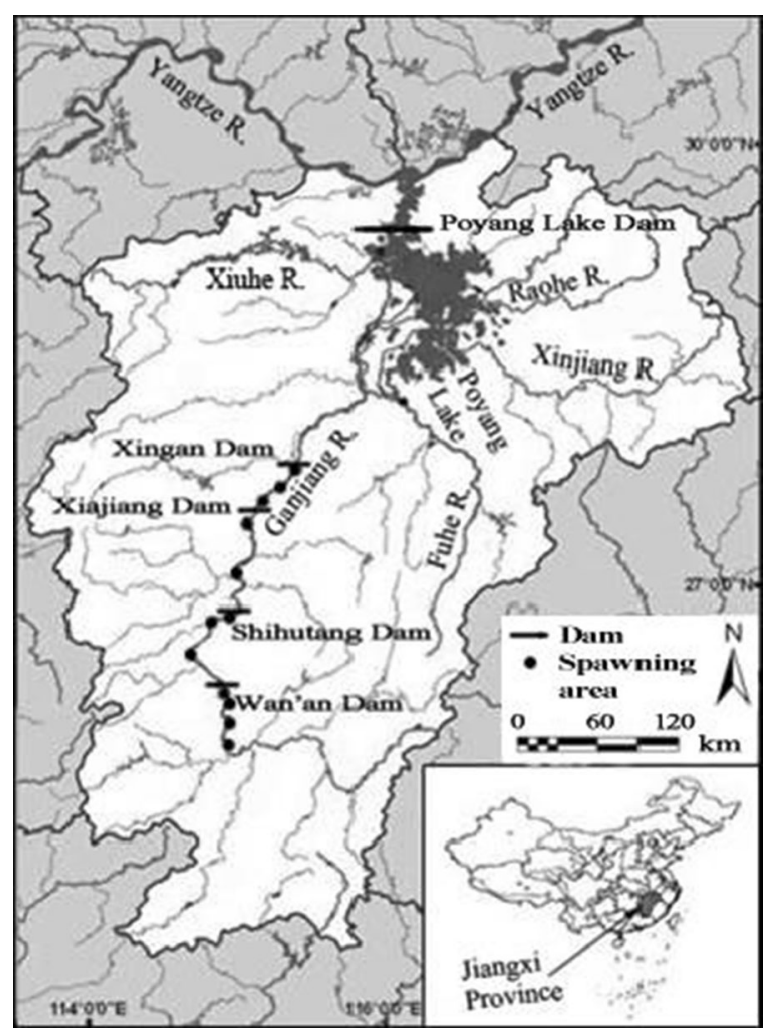

Fig. 1 Map of Poyang Lake, showing the inflowing rivers and the sites of the Poyang Lake Dam and other four dams in the Ganjiang River, Jiangxi, China 
Dam, and hence it is important to ascertain the abundance of larval carp in this river.

To date, there have been many studies reporting larval abundance of the four domestic Chinese carps in the Yangtze River before and after the completion of the Gezhouba and Three Gorges dams (Yi and Liang 1964; Yu 1985; Yi et al. 1988; Yu et al. 1988; Zeng 1990; Qiu et al. 2002; Duan et al. 2009; Jiang et al. 2010). However, larval abundance of the four domestic Chinese carps in the Ganjiang River has received little attention, and thus, little information is available for the management and protection of the four domestic Chinese carps in this river ecosystem.

Historically, there were 12 spawning grounds for the four domestic fishes in the Ganjiang River, distributed from Ganzhou to Xingan (a distance of $303 \mathrm{~km}$; Tian 1989). After the construction of the Wan'an Dam (completed in 1990), four spawning areas were flooded. Studies have shown that the abundance of fry drifting through Xingan section of the river each breeding season has decreased from 2.5 billion in the 1960s, 1.9 billion in the $1970 \mathrm{~s}, 1.3$ billion in the $1980 \mathrm{~s}, 0.5$ billion in the $1990 \mathrm{~s}$, to just 20 million in 2000 (Liu et al. 2009). Moreover, after the completion of the Wan'an Dam larval composition in the river also changed dramatically with silver carp now the most abundant larval species recorded, and a decline observed in the proportion of bighead carp.

Spawning in adult fishes is determined by external conditions, and is triggered in all four species by rising water temperatures $\left(>18{ }^{\circ} \mathrm{C}\right)$ and rising water levels. After the discharge peaks, spawning ceases. Hence, the construction of the Wan'an Dam has not only inundated existing spawning grounds above the dam, it has also caused a depression of spawning activities below the dam, because the regulated water flow does not behave like the natural hydrography of the river.

The future protection of the four carp species in the Ganjiang River will necessitate: 1) better knowledge of the distribution of their spawning grounds; 2) accurate quantification of the temporospatial dynamics in larvae abundance within the river; 3) a greater understanding of the relationship between patterns of larval abundance and environmental factors, such as discharge rates and quantities, both at the individual and population level; and 4) investigations to determine the influence of the Water Control Project on the larval abundance of the four carp species.

Acknowledgements The study was funded by the National Natural Science Foundation of China (No. 31360118), the Natural
Science Foundation of Jiangxi Province (No. 20122BAB214020), and the Education Foundation of Jiangxi Province (No. GJJ13090). The research was approved by the China Aquatic Wildlife Conservation Association.

Open Access This article is distributed under the terms of the Creative Commons Attribution License which permits any use, distribution, and reproduction in any medium, provided the original author(s) and the source are credited.

\section{References}

Borutsky EB, Wu X, Bai K, Ge M, Wang Q, Wang S, Chen S (1959) Hydrobiological survey of the region of the projected dam reservoir of Danjiangkou, with propositions for fisheries management. Acta Hydrobiologica Sinica 1:33-56 (in Chinese)

Bunn SE, Arthington AH (2002) Basic principles and ecological consequences of altered flowed regimes for aquatic biodiversity. Environ Manag 30(4):492-507

Duan X, Liu S, Huang M, Qiu S, Li Z, Wang K, Chen D (2009) Changes in abundance of larvae of the four domestic Chinese carps in the middle reach of the Yangtze river, china, before and after closing of the three gorges Dam. Environ Biol Fish $86: 13-22$

Fu C, Wu J, Chen J, Wu Q, Lei G (2003) Freshwater fish biodiversity in the Yangtze river basin of china: patterns, threats and conservation. Biodivers Conserv 12:1649-1685

Hu M, Wu Z, Liu Y (2011) Time course of the juvenile major Chinese carps in the hukou waters of Poyang lake. Resources and Environment in the Yangtze Basin 20(5):534-539 (in Chinese)

Huang F, Xia Z, Zhang N, Lu Z (2011) Does hydrologic regime affect fish diversity? -A case study of the Yangtze Basin (China). Environ Biol Fish 92:569-584

Jiang W, Liu H, Duan Z, Cao W (2010) Seasonal variation in drifting eggs and larvae in the upper Yangtze, China. Zool Sci 27:402-409

Li X, Huang D, Xie W, Xie S, Li P, Zhang Y (2006) Sqawning sites of four major Chinese carps in the middle reaches of Hanjiang River. Chinese Journal of Zoology 41(2):76-80 (in Chinese)

Liu B, Wu Z, Hu M, Zhang J, Zhu R, Chen Y, Zou S (2009) Spawning sites of four major Chinese carps in the middle reach of Ganjiang River. Jiangxi Science 27(5):662-667 (in Chinese)

Lytle DA, Poff NL (2004) Adaption to natural flow regimes. Trends Ecol Evol 19:94-100

McAllister DE, Craig JF, Davidson N, Delany S, Seddon M (2001) Biodiversity impacts of large dams. Background Paper 1, International Union for Conservation of Nature, and United Nations Environmental Programme, Gland, Switzerland.

Nilsson C, Reidy CA, Dynesius M, Revenga C (2005) Fragmentation and flow regulation of the world's large river systems. Science 308:405-408

Poff NL, Allan JD, Bain MB, Karr JR, Prestegaard KL, Richter BD, Sparks RE, Stromberg JC (1997) The natural flow regime. Bioscience 47(11):769-784

Qiu S, Liu S, Huang M (2002) The resources of four Chinese farm fishes in the middle reach of Yangtze River. Acta Hydrobiologica Sinica 26(6):716-719 (in Chinese) 
Richter BD, Baumgartner JV, Powell J, Braun DP (1996) A method for assessing hydrologic alteration within ecosystems. Conserv Biol 10:1163-1174

Tian J (1989) Fish resources in Ganjiang River before the construction of the Wan'an Dam and its fishery utilization. Freshwater Fisheries 19(1):33-39 (in Chinese)

Wan L, Cai Y, Tang H, Yang Z, Zhang X, Zheng H, Qiao Y (2011) Preliminary study on the larval resources of fishes spawning drifting eggs in the middle and lower reaches of the Hanjiang River. Journal of Hydroecology 32(4):53-57 (in Chinese)

Wang Z, Wu Q, Zhou J, Ye Y, Tong J (2003) Silver Carp, $a$, in the Poyang lake belong to the ganjiang river population rather than the changjiang river population. Environ Biol Fish 68:261-267

Wu X, Rao J, He B (1992) The history of the Chinese freshwater fisheries. In: Liu J, He B (eds) Cultivation of the Chinese Freshwater Fishes. Science Press, Beijing, China, pp 5-29 (in Chinese)

Xie P (2003) Three gorges Dam: risk to ancient fish. Science 302: 1149

Xie S, Li Z, Liu J, Xie S, Wang H, Murphy B (2007) Fisheries of the Yangtze river show immediate impacts of the three gorges Dam. Fisheries 32:343-344

Xie W, Huang D, Xie S, Yang H, Yu F, Zhang X, Lei H (2009) The early evolution of the four major Chinese carps resources in the middle and lower reaches of hanjiang river after the construction and operation of danjiangkou reservoir. Journal of Hydroecology 2(2):44-49 (in Chinese)

Yi B, Liang Z (1964) Natural conditions of the spawning ground and polisheds of the "domestic fishes" in Yangtze river and essential external factor for spawning. Acta Hydrobiologica Sinica 5:6-12 (in Chinese)
Yi B, Yu Z, Liang Z, Shan S, Xu Y, Chen J, He M, Liu Y, Hu Y, Deng Z, Huang S, Sun J, Liu R, Xiang Y (1988) The distribution, natural conditions and breeding production of the spawning grounds of four domestic freshwater fishes on the mainstream on the Yangtze River. In: Yi B, Yu Z, Liang Z (eds) Project and four domestic fishes in Yangtze river. Hubei Science and Technology Press, Wuhan, China, pp 1-46 (in Chinese)

Yu Z (1985) On spawning grounds of four Chinese farm fishes in the river changjiang after damming of gezhouba area. Transaction of the Chinese Ichthyological Society 4:1-12 (in Chinese)

Yu Z, Deng Z, Xu Y, Cai M, Zhao Y, Liang Z, Wang N, Zeng X (1988) The present situation of the spawning grounds of the four Chinese domestic fishes in the Yangtze River after the construction of the Gezhouba water control project. In: Yi B, Yu Z, Liang Z (eds) Gezhouba Water control project and four domestic fishes in Yangtze river. Hubei Science and Technology Press, Wuhan, China, pp 47-68 (in Chinese)

Zeng X (1990) Study on the promotion of natural reproduction of domestic fish by regulating water rising. Ecology 9(4):20-23

Zhang G, Lang W, Li H, Liu M, Cheng F, Murphy BR, Xie S (2012) Preliminary evidence of delayed spawning and suppressed larval growth and condition of the major carps in the Yangtze river below the three gorges Dam. Environ Biol Fish 93:439-447

Zhang Z, Mei P (1996) Effects of human activities on the ecological changes of lakes in China. GeoJournal 40(1-2):17-24

Zhou C, Liang Z, Huang H (1980) Ecological features of the spawning of certain fishes in the hanjing river after the construction of dams. Acta Hydrobiologica Sinica 7(2): 175-188 (in Chinese) 